\title{
INTRAUTERINE PREGNANCY AFTER SALPINGECTOMY FOR TUBAL PREGNANCY DUE TO EMERGENCY CONTRACEPTION: A CASE REPORT
}

\author{
Fabio Roberto Cabar, Pedro Paulo Pereira, Marcelo Zugaib
}

\section{INTRODUCTION}

Ectopic pregnancy (EP) is the fourth most frequent cause of maternal death in the United Kingdom, ${ }^{1}$ and it is the main cause of maternal death during the first trimester in the United States. ${ }^{2,3}$ The Fallopian tubes are the most frequently affected site by EP. The main causes of tubal pregnancy are salpingitis, previous tubal surgeries, and alteration in tubal motility mainly due to the use of certain contraceptive methods. ${ }^{4}$ Most recently, the use of $750 \mu \mathrm{g}$ of levonorgestrel as an emergency contraceptive method has been identified as another risk factor for EP. ${ }^{5-8}$

The diagnosis of an EP before rupture permits conservative treatment in order to preserve subsequent patient fertility. However, the conservative approach might be questioned because it is associated with a higher recurrence rate when compared with salpingectomy. ${ }^{9}$ Additionally, salpingectomy does not change subsequent patient fertility when (i) the contralateral tube seems to be healthy, ${ }^{10}$ (ii) the patients are younger than 30 years, ${ }^{11}$ and (iii) there is no previous history of infertility. ${ }^{11,12}$ In these patients, subsequent intrauterine pregnancy rate reaches approximately $70 \%$ at 2 years.

We report here a case of intrauterine pregnancy (IUP) that occurred after salpingectomy in a patient previously undergoing tubal pregnancy without any apparent risk factors for EP other than the use of emergency contraceptive pills containing $0.75 \mathrm{mg}$ levonorgestrel (Postinor $2^{\circledR}$ ).

\section{CASE REPORT}

A 28-year-old woman spontaneously conceived an IUP after salpingectomy performed due to tubal pregnancy. She quit taking oral contraceptives on July 2005, and the diagnosis of IUP was established on September 2005; the transvaginal ultrasonography showed an intrauterine gestational sac with a beating-heart embryo and an image of the corpus luteum in the left ovary. The pregnancy development was uneventful and resulted a healthy newborn.

Two years before the IUP, the patient sought care at the Emergency Obstetric Service of Hospital das Clínicas, University of São Paulo, a university hospital in São Paulo with complaints of hypogastric pain irradiating to the left iliac fossae and a small amount of genital bleeding of a 2-week

University of Sao Paulo, Faculty of Medicine - Obstetrics and Gynecology, São Paulo/ SP, Brazil

Email: fabiocabar@uol.com.br duration. There was a 5-week menstrual delay. The patient reported an episode of unprotected sexual intercourse 13 days after the last menstrual period, which was followed by the correct use of Postinor 2. Thirty-four days after the use of the drug, the patient noted a small amount of vaginal bleeding that persisted until the time of the visit. The onset of progressive pelvic pain was 3 days before the hospital visit. She was nulligravida and had no pelvic infections.

Examination of the patient at admission showed good general health, and she was hemodynamically stable. The abdomen was soft and discretely tender upon deep palpation of the hypogastrium and left iliac fossae, with painless sudden decompression. There was a small amount of blood discharged into the posterior vaginal fornix, with no bleeding through the external orifice of the cervix. The vaginal exam revealed an anteverted uterus of normal size and a left adnexal pouch that was tender upon combined palpation. An irregular mass was detected that led to bulging of the posterior vaginal fornix.

The urinary hCG test was positive. Ultrasonography identified an uterus with normal dimensions, a 9-mm centered endometrium, and an empty cavity. The right and left ovaries were normal. An oval and heterogeneous image measuring $34 \times 36 \times 25 \mathrm{~mm}$ was visualized close to the left ovary in addition to a minimal amount of free fluid in the Douglas' cul-de-sac. Serum $\beta$-hCG was 6054 mIU/ $\mathrm{mL}$ upon initial determination.

After establishment of the diagnostic hypothesis of tubal pregnancy, the patient underwent laparoscopy, which was performed without complications. During surgery, a small amount of free blood in the pelvis and an intact left uterine tube with a saccular formation in it was observed. Left salpingectomy was performed since the contralateral tube seemed normal, the patient was younger than 30 years, and there was no previous history of infertility. The excised tissue was sent for anatomopathologic examination, which showed normal embryologic tissue with necrosis and hemorrhagic areas.

\section{DISCUSSION}

In this case report, at the time the patient had an EP, laparoscopy showed that the contralateral tube was undamaged. The patient reported no risk factor for EP other than the use of $0.75 \mathrm{mg}$ Levonogestrel. Even though the affected tube was intact, salpingectomy was performed in order to resolve the problem. 
It is already known that salpingectomy does not change subsequent patient fertility when the contralateral tube seems to be healthy. Tuomivaara and Kauppila $(1988)^{10}$ reported subsequent rates of intrauterine pregnancy and EP of $85 \%$ and $9 \%$, respectively, in the presence of a normal contralateral tube irrespective of the type of treatment performed. Fernandez et al (1998) ${ }^{11}$ studied 340 patients who underwent salpingectomy for EP after a mean follow-up period of 73 months; they observed a subsequent intrauterine pregnancy rate of $82.1 \%$ in patients younger than 30 years with no history of tubal disease, a rate similar to that obtained for another group managed conservatively. Mol et al $(1998)^{13}$ evaluated 135 patients undergoing surgery for $\mathrm{EP}, 56$ receiving conservative treatment and 79 undergoing salpingectomy, and found no significant difference in subsequent intrauterine pregnancy rates between the 2 groups. In this case, the patient was 28 years old, and there was no previous history of infertility.

Some authors have suggested that the conservative approach may be associated with a higher recurrence rate when compared to salpingectomy. ${ }^{9}$ They state that Fallopian tubes affected by EP frequently show morphologic and functional alterations, such as persistent foci of decidual transformation, diverticula, or postinflammatory changes ${ }^{14}$ and that these abnormalities may persist after conservative treatment. In addition, implantation of trophoblastic tissue into the tubal wall may impair oviductal function either by altering the ciliary epithelium or mainly by causing architectural derangement of the wall musculature due to an inflammatory reaction, increasing the risk for a new episode of EP. So, although it is important to avoid the removal of less compromised structures in order to improve the reproductive prognosis, it is essential to avoid preserving extensively damaged tubes, which markedly increase the mor- bidity resulting from a new EP episode.

It is believed that impairment of tubal function depends on the degree of invasion of the trophoblast into the tubal wall. ${ }^{14}$ Cabar et $\mathrm{al}^{15}$ showed that $\beta$-hCG concentration is the best predictive factor of trophoblastic invasion into the tubal wall; they reported that cases with $\beta$-hCG levels above $5990 \mathrm{mIU} / \mathrm{mL}$ showed a 13.9 times greater probability of complete tubal infiltration compared with the other cases selected, with $82.6 \%$ sensitivity, $74.6 \%$ specificity, and $78.1 \%$ accuracy. The high serum $\beta$-hCG levels seem to be associated with destruction of the tubal wall, and invasion of the muscle layer may impair the complete removal of trophoblastic tissue if a conservative therapeutic approach is used. In this case, serum $\beta$-hCG was $6054 \mathrm{mIU} / \mathrm{mL}$ upon initial determination, which indicated that radical surgery might be the best therapeutic approach.

The IUP occurred 2 month after the patient had quit taking oral contraceptives, and the ultrasound showed an image of the corpus luteum on the left ovary. That indicated that the right tube was functional, since it was able to capture the oocyte released on the opposite side.

The only risk factor for EP reported by the patient was the use of emergency contraception. We already have reported 2 cases of EP after levonogestrel intake. ${ }^{5}$ Special attention should be paid to patients who use emergency contraceptive methods and complain of genital bleeding and/ or abdominal pain, in an attempt to anticipate the diagnosis of EP and thus improve therapeutic conduct.

We conclude that salpingectomy does not impede future intrauterine pregnancy, especially when the contralateral tube seems normal; conservative treatment should be offered to selected cases. Emergency contraception is a risk factor for ectopic pregnancy, and women should be alerted about this possibility.

\section{REFERENCES}

1. Lewis G and Drife J. Why mothers die-triennial report 2000-2002. In: The sixth report of the confidential enquiries into maternal deaths in the United Kingdom. London: RCOG Press; 2004.

2. Centers for Disease Control and Prevention. Ectopic pregnancy-United States, 1990-1992. MMWR Morb Mortal Wkly Rep. 1995;44:46-8.

3. Grimes DA. The morbidity and mortality of pregnancy: still risky business. Am J Obstet Gynecol. 1995;170:1489-94.

4. Cunningham FG, Leveno KJ, Bloom SL, Hauth JC, Gilstrap LC, Wenstrom KD. Ectopic pregnancy. In: Cunningham FG, Leveno KJ, Bloom SL, Hauth JC, Gilstrap LC, Wenstrom KD, editors. Williams Obstetrics, 22nd ed. New York: McGraw-Hill; 2005. p. 254.

5. Pereira PP, Cabar FR, Raiza LC, Roncaglia MT, Zugaib M. Emergency contraception and ectopic pregnancy: report of 2 cases. Clinics. 2005;60:497-500.

6. Gainer E, Mery C, Ulmann A. Ectopic pregnancies following emergency levonorgestrel contraception. Contraception. 2004;69:83-4

7. Basu A, Candelier C. Ectopic pregnancy with postcoital contraceptiona case report. Eur J Contracept Reprod Health Care. 2005;10:6-8.

8. Jian Z, Linan C. Ectopic gestation following emergency contraception with levonorgestrel. Eur J Contracept Reprod Health Care. 2003;8:225-8.
9. Yao M, Tulandi T. Current status of surgical and nonsurgical management of ectopic pregnancy. Fertil Steril. 1997;67:421-33.

10. Tuomivaara L, Kauppila A. Radical or conservative surgery for ectopic pregnancy? A follow-up study of fertility of 323 patients. Fertil Steril. 1988;50:580-3.

11. Fernandez H, Marchal L, Vincent Y. Fertility after radical surgery for tubal pregnancy. Fertil Steril. 1998;70:680-6.

12. Ego A, Subtil D, Cosson M, Legoueff F, Houfflin-Debarge V, Querleu D. Survival analysis of fertility after ectopic pregnancy. Fertil Steril. 2001;75:560-6.

13. Mol BW, Matthijsse HC, Tinga DJ, Huynh T, Hajenius PJ, Ankum WM, et al. Fertility after conservative and radical surgery for tubal pregnancy. Hum Reprod. 1998;13:1804-9.

14. Green LK, Kott ML. Histopathologic findings in ectopic tubal pregnancy. Int J Gynecol Pathol. 1989;8:255-62.

15. Cabar FR, Pereira PP, Schultz R, Zugaib M. Predictive factors of trophoblastic invasion into the ampullary region of the tubal wall in ectopic pregnancy. Hum Reprod. 2006;21:2426-31. 